\title{
Recommendations for conducting controlled clinical studies of dental restorative materials
}

\author{
R. Hickel • J.-F. Roulet • S. Bayne • S. D. Heintze • \\ I. A. Mjör • M. Peters • V. Rousson • R. Randall • \\ G. Schmalz $\cdot$ M. Tyas $\cdot$ G. Vanherle
}

(C) Springer-Verlag 2007

\section{Erratum to: Clin Oral Invest (2007) \\ DOI 10.1007/s00784-006-0095-7}

The conflict of interest statement was missing from the original publication.

Conflict of interest statement All authors declare that they have no conflict of interest. Prof. J.-F. Roulet is Director of R\&D clinical; Dr. S. Heintze is Head of the in vitro Laboratory; Ivoclar Vivadent, Bendererstr. 2 Fl-9494 Schaan. Dr. R. Randall is Technical Manager of 3MESPE Dental, St. Paul, MN, USA. By publication they DO NOT have any benefits or other advantages.

The online version of the original article can be found at http://dx.doi. org/10.1007/s00784-006-0095-7.

\section{R. Hickel $(\square)$}

Department of Operative Dentistry and Periodontology,

University of Munich,

Goethestraße 70,

80336 Munich, Germany

e-mail: hickel@dent.med.uni-muenchen.de

J.-F. Roulet · S. D. Heintze

Ivoclar-Vivadent AG,

Schaan, Liechtenstein

\section{S. Bayne $\cdot$ M. Peters}

Department of Cariology, Restorative Sciences, and Endodontics, School of Dentistry,

Ann Arbor, MI, USA

\section{A. Mjör}

Department of Operative Dentistry, University of Florida,

Gainesville, FL, USA
V. Rousson

Department of Biostatistics, ISPM, University of Zurich, Zurich, Switzerland

R. Randall

3M ESPE Dental,

St. Paul, MN, USA

G. Schmalz

Department of Operative Dentistry and Periodontology, University of Regensburg,

Regensburg, Germany

M. Tyas

School of Dental Science, University of Melbourne, Melbourne, Australia

G. Vanherle

Department of Operative Dentistry and Dental Materials, Catholic University Leuven,

Leuven, Belgium 